\title{
Preparation for Facing the era of the industrial revolution 4.0
}

By : Dika Anggara Putra

NRP: 130119046

In the era of the industrial revolution 4.0 human resources were threatened and to adapt in this era the Indonesian government made manufactures that could have global competitiveness. in the case of the industrial revolution 4.0 the use of technology, information and communication is growing rapidly in a series of production processes that are being carried out to achieve efficiency and increase the quality of production.

In the era of the 4.0 industrial revolution, it was also marked by the use of information technology, artificial intelligence, and automatic machines or vehicles that have been going on since 2011, where these machines have been integrated with the internet network and even some countries have been able to make it happen more efficiently by integrating industrial production systems.

For example the automotive industry, automotive industry players in Indonesia have utilized several technologies that lead to efficiency, such as three-dimensional printing technology and robotic technology. Competitive advantage today and in the future has become a necessity for every business actor when he wants to compete in the global market. This condition will encourage change at all levels and business units because every business actor can enter other countries to market easily, considering that there are no real boundaries so that the professionalism of each actor's business is highly prioritized as seen in business decision making and sustainable innovation.

One of the determinants of being able to innovate without stopping is the readiness of the business world to build and prepare human resources that are superior and of global quality, in the sense of having talents with high standard competencies in their respective fields and having a strong character that is able to compete at the global level. Indonesia desperately needs superior human resources as basic capital, considering the disruption of technology that marks the 4.0 industrial revolution has changed the political and economic order which resulted in the loss of many jobs being replaced by technological processes.

In general, employee work productivity is directly proportional to the high competitiveness of the organization's company as a whole in facing business competition, because everything is closely related to the level of staffing satisfaction with the company organization, which includes guaranteed more competitive salaries, better career guarantees, a comfortable work environment, and the benefits of the facilities offered. Employees who are employed are employees who are competent and able to give a high commitment to the company and are satisfied with what the 
company has given them. Employee involvement or involvement is strongly influenced by various factors, such as supervisor behavior, employee compensation, and employee-related policies. A superior company is a company that is competitive and is always adaptive to change. It must be understood that in the midst of a business environment that is always changing and rapidly changing, only companies that are adaptive to change are able to survive in the global era, even grow and develop consistently. To make changes, companies often go massively and radically, abandoning the old ways, and turning to new and more efficient ways and methods. New ways and methods that are implemented by companies usually require business transformation and human resources transformation. Transformation will run well if the company has a strong organizational culture. Corporate culture is very important because it serves as a strong adhesive between company members as well as a united movement and steps for all elements in the company. The worrying thing is about the low quality of human resources in Indonesia with low achievement where formal education and basic competence of students are low because access to education, quality of education, and educational disparities are still far behind other countries.

Individuals in the era of the industrial revolution 4.0 must be given the opportunity to develop uniqueness that is more valuable than just money, power and rank. This can trigger employee effectiveness at work and can increase employee loyalty at work. Which makes them have creativity and innovation. In facing the era of the industrial revolution 4.0, humans must also have more value so that they cannot be replaced by machine technology. Therefore, companies also have an obligation to develop their human resources by innovating. Innovation itself is not only finding a new and unique product but developing strategic work, synergizing with each other, and collaborating with partners to form strong coordination is also part of innovation.

For example, PT TELKOM, PT PELINDO, and PT ASTRA, these companies have developed their human resources. Like PT TELKOM, it starts with building character, competence, collaboration, and teamwork to generate many talents and market appraisal to achieve global success. In PT PELINDO started human resource development through strengthening corporate culture and corporate values by prioritizing changes in behavior and mindset. Employee competency enhancement is carried out through training programs and customer care officers. Meanwhile, PT ASTRA is based on the interests of the business unit and the interests of individuals known as the Astra Roadmap. Leadership development at astra is based on employees identified as talents and is carried out comprehensively through integrated talent management, assignments, and mentoring to improve leadership competencies. Other programs to achieve superior human resources include benchmarking, FGDs, case studies, and employee involvement in training modules organized by various external agencies.Behind all that, company leaders have challenges that can be said to be quite heavy because they have to provide direction to each individual concerned to realize their vision and mission in the midst of changing dynamics that are currently rife with the involvement of every individual. 
In conclusion, Indonesia desperately needs superior human resources to face the 4.0 industrial revolution that demands smart factory operations, smart services, and innovative products. The type of work to be done that is affected first is work that is done repeatedly. This type of work will be replaced by artificial intelligence through automation. Going forward, the war on talent will be at the top of the agenda for corporate leaders in the digital economy era and they seek to make talent management a core business, including changing the mindset of employees in relation to managing company assets. Basically, individual performance management systems are drivers of individual performance, and can support organizational performance.

Talent must be able to work together in applying competencies in order to obtain optimal and sustainable results, and companies are expected to build organizational capabilities that are reflected in strategic and performance management, given that the level of organizational capabilities in management strategy and execution with company performance has a close relationship.

\section{References}

Tayibnapis, A. Z., Wuryaningsih, L. E., \& Gora, R. (2018). International Journal of Humanities and Social Science Invention. Indonesia's Efforts to Achieve Globally Comptitive Human Resources, 7(08), 01-06. 